\title{
Historical and Mythical Time in the Marvel and DC Series
}

\author{
MARCELLO SERRA
}

$\mathrm{T}$

HE WORLD OF SUPERHERO COMICS IS, WITHOUT ANY DOUBT, A VERY complex and heterogeneous universe. Nevertheless, as can often happen, if we look from a greater distance to the entirety, we can observe some forms of systemic coherence throughout. Using an alternative lexical approach, we can say that these comics create a semiosphere (Lotman, "On the Semiosphere"), a universe of significance that works by general rules of semiotical functioning. In particular, if we focus on the differences between Marvel and DC comics - the so called "Big Two" publishing houses that dominate in sales and in the cultural pervasiveness of their imaginaries (Duncan and Smith 89-92)—we notice how they reciprocally define each other by a few basic oppositions. For instance, and very importantly, these two serial systems differ in their conception of temporality.

On this subject, Umberto Eco, talking about DC's most famous hero in his seminal article "The Myth of Superman" (originally published in 1962), commented that his adventures occurred "in a kind of oneiric climate - of which the reader is not aware at all-where what has happened before and what has happened after appear extremely hazy" (114). Eco observed that between one episode and another in the series there was no chronological succession or continuity between corresponding issues. Furthermore, the stories frequently "concern events already told but in which 'something was left out,' so they are told again from another point of view, and in the process lateral aspects come to the fore" (115). Therefore, according to his analysis,

The Journal of Popular Culture, Vol. 49, No. 3, 2016

(C) 2016 Wiley Periodicals, Inc. 
In this massive bombardment of events which are no longer tied together by any strand of logic, whose interaction is ruled no longer by any necessity, the reader, without realizing it, of course, loses the notion of temporal progression. Superman happens to live in an imaginary universe in which, as opposed to ours, causal chains are not open (A provokes $\mathrm{B}, \mathrm{B}$ provokes $\mathrm{C}, \mathrm{C}$ provokes $\mathrm{D}$, and so on, ad infinitum), but closed (A provokes B, B provokes $\mathrm{C}$, $\mathrm{C}$ provokes $\mathrm{D}$, and $\mathrm{D}$ provokes $\mathrm{A}$ ), and it no longer makes to talk about temporal progression on the basis of which we usually describe the happenings of the macrocosm. (115-116)

All of this is possible thanks to the kind of seriality adopted: An iterative seriality characterized by autoconclusive episodes, whose order is practically irrelevant.

These considerations, written in the early 1960s and based on the reading of the previous decade's comics, still hold some descriptive value and interest today. Nevertheless, in the same years in which Eco was writing, the Marvel publishing house introduced serial forms that differed from DC's in that, among other things, they developed in time and created what Richard Reynolds calls "serial continuity" (38), which "helped to make the fantasy world that much more real, or at least more like the one in which fans lived" (Pustz 113). So, today, as in the past, the Marvel universe orders events in a timeline, and the characters accumulate an experience that they did not have at the beginning; in other words, a consistency of narrative occurs across several separate issues that provide the reader with a "back story" (Reynolds 38). This does not mean that its series are exempt from temporal paradoxes (in fact, they are full of them). Instead, from a more general point of view, the different serial organizations of Marvel and DC end in two opposite conceptions of time, situated at the two extremes of a continuum of possible temporalities. As firstly observed by Daniele Barbieri (124-26), while the DC seriality is based on a temporality that tends to be mythical (or cosmological), which in its ideal form works as Eco describes, the Marvel series leans toward a more historical temporality.

The Russian semiotician Boris Uspenskij presents these two models in the following way:

The historical approach organizes events relating to our past into a causative series. Events of the past are consecutively viewed then as the result of some other, earlier events. Thus the historical 
consciousness always presupposes a reference to some preceding situation-but not the initial one! - which, in turn, is causally related to yet another, even earlier, preceding situation, and so on. The cosmological approach, on the other hand, entails the relation of events to a certain primeval state, a first time, which never disappears in the sense that its effects continue to be realized throughout the temporal process. Events which occur in this primeval time form a text which is constantly repeated (reproduced) in the events that follow. This ontologically initial text which, in one way or another, is related in our consciousness to all following events corresponds to what is customarily understood by the concept of "myth." (21)

For the historical consciousness, the importance of present events depends on their future projection, on their possible effects and consequences. On the contrary, in the field of the cosmological consciousness the events are relevant for their relationship with the past. They present themselves not as a cause of future events, but as consequences and reflexes of precedent stages that determine them. In other words "the present is not viewed as anticipating the future, but it is viewed as a manifestation of an initial state" (Uspenskij 22).

Clearly, the temporalities of Marvel and DC do not perfectly follow the temporalities described by these two ideal models. The respective histories of these two publishing houses are very long and their narrative systems have changed over time (Puszt 130-32; Jenkins 20-21). In the seventies, the DC series started to exhibit certain linearity, and then, after Crisis on Infinite Earths (1985-1986), an event that signified a radical change in the DC fictional world structure, they tried to build a continuity similar to the one adopted by Marvel. However, the typical iterativity of its Golden Age series did not totally disappear and left its mark on both the organization and conception of this universe. As we have seen with Eco, in the iterative serial model, the predominant temporality is the cyclical one and, as a result, the system, to some degree, obeys the logic of the cosmological conscience.

Even if Marvel's seriality presents elements that belong to cyclic time, compared with the DC seriality it is certainly very much closer to an historical temporality. In its series the time flows in a linear direction and all the events, at least in principle, are meaningful; they accumulate and they construct a memory. Characters and readers, 
because of the linearity of these adventures, have to forcibly bear in mind a past that becomes richer month after month.

On the contrary, even though DC aligned itself close to the Marvel model after Crisis on Infinite Earths, its characters remain more fixed, and the stories, in general, are more "timeless." Thus, the origin stories are very important in this universe. They are told frequently and in different ways, yet still emphasize the fundamental characteristics of the heroes, the semantic features that make them what they are and what they will ever be. Certainly, the origin story must be considered as an important feature of the superhero genre in its entirety; according to Alex S. Romagnoli and Gian S. Pagnucci, for example, it "helps to make superhero narratives a unique literary genre" (3), and Duncan and Smith suggest that it "is probably the most familiar superhero story" (231). In the DC universe, the origin stories end up being essential to the overall organization of the system. This attention to origins is typical of the mythical cosmology, where something that has already happened, and is known by the public, is the object of continuous retelling. Variations and additions do not modify the essence of myth, and it is no coincidence that, even though they are a constant in the DC history, there was a proliferation of superhero origin stories after Crisis on Infinite Earths (with the appearance of the Secret Origins magazine) and the same occurred again after the more recent Infinite Crisis (2005-2006). On these two occasions, the DC universe suffered a profound reorganization that, in a system with mythical characteristics, had to coincide with a new beginning (and with new origins of the heroes). This is because, as the great mythologist Eleazar Meletinski tells us, "the fundamental characteristic of the myth... resides in the fact that it links the essence of things to its genesis; to illustrate the structure of something means to recount how it had been created; to describe the world is the same as to tell the story of its creation" (164).

In the history of DC comics, it has always been more difficult for an event to become part of the official history of the universe. In other words, even if they could remain in the memory of the readers, many events did not enter the memory of the characters because, as Meletinski says regarding historical facts in a myth-based culture, they had (and still partly have) to dispose themselves "in the procrustean bed of an already prepared mythical structure, and they 
become an imperfect reproduction, a repetition of its absolute prototype, situated in the mythical time" (169).

In this way, each version of a superhero represents nothing more than an embodiment of a few basic principles, but from another point of view, they are malleable figures. For example, as observed by Marco Arnaudo, in Superman's origin some elements can be attributed to Jewish tradition, but, at the same time, there are also many stories in which Superman shows Christic connotations (32). In a similar way, it is possible to have different interpretations for each one of the DC's superheroes, and the same applies to Marvel's characters, although with less clarity. ${ }^{1}$ When examining these different versions, says Arnaudo, "it is therefore not a question of determining which reading is 'right' or 'wrong"' (32); this is because these versions manifest the semantic polyvalence of these characters, whose fundamental core of significance can be enriched and completed in the most varied of ways. If we apply the Yuri Lotman definition of symbol, this is what superheroes are: Something that possesses various potential meanings that are always "much wider than one given realization of them" (La semiosfera I, 146). This elasticity, due to "a certain undefined character in the relationship between the textexpression and the text-content" (146), is what enables the mythical function of the DC superheroes, because all the bonds that the symbol can find in a specific semiotical realm do not drain all its valences of significance and "this is precisely what creates that reserve of meaning with whose help the symbol can enter into unexpected relationships" (146).

In addition, the symbolic nature of these characters allows a certain coherence, or at least a certain unity, within the lack of homogeneity typical of a seriality with an iterative tendency like that of DC's. This is possible because, as Lotman observes, symbols are an important mechanism of memory and "they transport texts, models, sujets and other semiotical patterns from one cultural layer to another," or, for our purposes, from one (publishing) era to another. In this way, "the constant repertoires of symbols which cross the diachrony of the culture take on, in a large portion, the function of unity mechanisms: In realizing the memory of the culture, they do not allow it to disintegrate in isolated chronological layers" (145). In other words, in a universe with a continuity which is not strict, and in certain eras does not even exist, the unity of the narrative world does not come from the 
"historical" coherence of a timeline but, to some degree, from the memory which comes from the symbolic value of the characters.

Going back to Marvel's comics - and always keeping in mind that, like DC's, they are not examples of a "pure" temporality model - the relevance of events has always been determined by their future projection, thus following the historical pattern, in which the future is perceived as an evolution. This is perfectly evident in the fan discourse, vocally passionate about the possible evolution of the series and very attentive to leads that can imply future events, as, for example, the comeback of a character who was considered dead.

This is possible because all the past, and not only the origin, is relevant, and affects the present of these superheroes. This idea of historicity and linear progression, for example, has enabled Marvel to publish some "imaginary" stories, with the subtitle of "The End," where the conclusion of the characters' adventures and, sometimes, the story of their deaths are recounted. Even if these comics are outside of continuity, the logic that sustains this operation is the idea of finding the ultimate consequences of a chain of past events, which are, even if no reference is made to them, considered as implicit causes. Hence, these stories show how the structural weight of the narration in Marvel does not only reside in the origin but also in the possibility of an ending.

On the other hand, in DC's comics the constant question seems to be "Where does it come from?" The emphasis is placed on the beginning, and the semiotic status of present events is that they are not causes but consequences; they are "preordained by events of the primeval time" (Uspenskij 22). Thus, the death of a DC hero has normally occurred in one of the crises that revolutionized the universe and implied a new origin, confirming the cosmological nature of this fictional world.

Over the last thirty years these two serial systems have moved quite close together by progressively adopting some of each other's attributes. Nevertheless, the respective tendencies to the opposite poles of temporality still have some influence on the narratives. An interesting example is seen in the differences between the "imaginary" stories of the two publishing houses.

Because of continuity, the Marvel series have always created a timeline, a past, and a more or less coherent archive of memories where every recounted event has its place. Nevertheless, over the 
years, Marvel has published several stories set outside of continuity, "imaginary" narratives which do not respect the history of the universe and infringe upon the rules of seriality; they are autoconclusive stories that do not allow for any possible further development, even if they suggest it. The most important are the ones published under the What if...? brand; here, following a counterfactual logic, "the roads not traveled" by the various Marvel characters are explored.

From a structuralist point of view, it is interesting to observe that DC has a counterpart in the Elseworlds series, which is very similar to the What if...? but presents a few slight but substantial differences that respond to the distinct temporal logics on which the two big superhero universes are based.

The What if...? series (twelve to date) all have a similar narrative structure. In the first (1977-1984) and second (1989-1998) series, the stories are told by a narrator, Uatu the Watcher, who, as an observer of the Earth's events, is able to see what happens in the alternative realities. In the subsequent series, the narrators are various and sometimes absent; however, the idea is the same: the authors take an important event in the continuity and imagine what would happen if things were to have taken place in a different way. The first issue of the first series was entitled What if Spider-Man Had Joined the Fantastic Four? and, over the years, different authors have wondered, for example, about the possibility of Iron Man being a traitor or Karen Page, Daredevil's former girlfriend, not actually dying. In other words, the idea is to look for a divergence point, an explosive moment in which things could have taken another direction and to imagine the consequences of a different result in its history.

As Daniele Barbieri observed, the What if...? series represents an escape from the temporal continuity of the Marvel series and a manner of experimenting with the iterative narrative that is absent in its system (53). Even so, this kind of narrative structure is possible only within an historical conception of time, where the present is seen in the light of the past and interpreted as a consequence of it; in this way, any other path of history that differs to the one that occurred is considered unreal, but it is necessary to admit the possibility that the facts could have taken another direction. So, Uspenskij's considerations on these temporal issues seem almost to be a description of the What if. . .? series: 
The present, in its turn, may also be conceptualized by an analogy to the future, that is, the experience of perceiving the future may, in a secondary way, be applied to the present. Just as one may model (predict) the future, basing this prediction on the present, one may also make a conventional model of the present based on the past, starting from the past and evaluating unrealized possibilities (that is, asking questions such as: What would have happened had the past flowed differently? How can events that might have happened in the past be reflected in the present?). (122)

Similarly, the future is not predetermined but is the result of the directions taken at each point of bifurcation (when it becomes irreversible). From this point of view, the history ensues to be an asymmetrical and irreversible process and, retaking Marc Bloch's image $(\mathrm{xxx})$, presents itself as a strange film, which, if projected in reverse, would never arrive at the first frame. Thus, this perspective leads to a specific historiographical view, one that directs us to analyze the events that actually took place on the background of a field of nonrealized possibilities. In this sense, Uspenskij considers that "this possibility of modeling the historical process by turning to the past, thus replaying and reconsidering various situations that might have occurred but did not actually occur, appears to determine the methodological specificity of history as a scholarly discipline" (123). And Lotman, defending the same perspective, observes that, from the point of view of the historical interpretation, "the paths not travelled are as real as the travelled ones" (La semiosfera I, 254). So, Clio, the muse of history, "presents herself not as a passenger in a wagon that rolls on the tracks from one point to another, but as a pilgrim who goes from crossroads to crossroads and chooses a path" (254).

In this sense, the What if...? comics represent a reflection on the history of the Marvel universe, and they fit perfectly in a linear conception of time. ${ }^{2}$ In this regard, the presence of a narrator is eloquent: Uatu is a witness and, at the same time, an entity who, as an historian, observes the events from a distance, from a remote point of view which makes the account of all the events possible, that is, enabling the establishment of causal relationships and the construction of interpretation patterns. In theory, Uatu is free from the complex bundle of passions and interests that envelop the present; he can observe these old events as "facts" and old comics as historical sources, which can be used as a starting point to imagine different 
historical possibilities. This speculative operation is especially meaningful, because describing the "alternative paths" of history and pinpointing the most crucial divergence points is a way of highlighting the importance of certain events for the present. For this reason, the What if...? series is, among other things, a way of thinking about the present of the Marvel universe and of clarifying which past events are relevant now and for what reason. In other words, it is a way of reinforcing the (historical) cohesion of this fictional world.

Things are different in DC's Elseworlds. These comics inherit the long tradition of the Imaginary Tales, which appeared in the first years of the publishing house (the first is dated 1942) and were published until 1986. Then, after Crisis on Infinite Earths, they were replaced by the Elseworlds, which proved to be a version with even bigger narrative freedom. Here, according to its tagline, "heroes are taken from their usual settings and put into strange times and places - some that have existed, and others that can't, couldn't or shouldn't exist. The result is stories that make characters who are as familiar as yesterday seem as fresh as tomorrow."

Unlike the What if...? stories, Elseworlds' narratives do not have a narrator $^{3}$ and develop as a normal comic, but are situated outside continuity. (This is not a rule exempt from exceptions, however.) The main differences between the two series lie in the fact that Elseworlds is not based on the idea of a point of divergence, but transfers the myths to other environments, reaffirming its universality and atemporality. For example, in Superman: Red Son (2003) writer Mark Millar imagines that the Man of Steel would have been raised in the Soviet Union and become Stalin's successor. The environment in which the story develops could not be more different from Superman's normal world, but many of the elements that build the traditional fictional world are present. His eternal rivalry with Lex Luthor remains unchanged, The Daily Planet, Lois Lane, Lana Lang, Brainiac all exist, and the secret romantic tension that defines his relationship with Wonder Woman is maintained. However, the presence of these elements is only necessary in order for the reader to understand that the crux is still the same and that all the changes do not alter, but cast a new light on the fundamental questions which define the myth of Superman: What would happen if an alien with superpowers and a deep love for humanity arrived on Earth? How would he act if he 
was raised here and felt part of the human race? What right would he have to use his superpowers to change the destiny of humanity?

So, as Henry Jenkins summarizes, "The Elseworlds books read the superheroes as archetypes who would assert themselves in many different historical and generic contests; they invite a search for the core or essence of the character even as they encourage us to take pleasure in their many permutations" (24). In other words, these stories recount variants of the different superheroes thus making a translation of the myth. In this operation, as it is easy to imagine, the elements that always remain the same are the ones that correspond to the mythical core of the character. In this way, we see the reaffirmation of the basic values of the myth, the invariant features fixed by the origin. It is here that the Elseworlds-whose logo has, incidentally, a circular design-reveal themselves as an expression of cosmological consciousness: In these stories the myth is like an "always," an omnipresent moment that is replicated in every possible reality.

We can better understand all this by observing that, as the same title suggests, the questions put on the table in the Elseworlds seem to be more related to space than to time; and, once more, this can be explained by the tendency of the DC universe to lean toward a cosmological temporality pattern. Here, all that happens presents itself "as the reflex of an original state" and "the time is seen not as constantly arising, but as existing" (Uspenskij 27); in addition, if the perception of the future of an historical consciousness is based on the idea of evolution, the cosmological one is founded on the idea of predetermination. Throughout this discourse, what is mostly interesting for our argument is that

The cosmological model of time naturally gives rise to associations between time and space, or at least such associations are foregrounded in this case. Indeed, to say that the future exists, but is not yet known to us is virtually equivalent to saying that it exists somewhere else, that is, in a different place which is inaccessible to us, but whose reality is beyond a doubt. And also the past may be seen as located in another place where we have already been (a place which at that time was part of our experience). In this way the perception of space is carried over to the perception of time: Time is conceptualized in spatial models and spatial categories.

(Uspenskij 27) 
Time coincides with space, and past and future exist in another place from present; interestingly, this had been precisely true for many years in the "official" organization of the DC universe too, and not only in the imaginary stories. Indeed, from the beginning of the 1960s to the 1985-1986 Crisis, the Golden Age versions of the various superheroes lived on another Earth, called Earth-Two, a universe that was parallel to the one where the primary version of the same characters used to live. ${ }^{4}$ In addition, during these years, the DC world presented itself as a multiverse made by various parallel Earths, all of them provided with their own continuity. This structure, which represented the highest expression of the mythical nature of the DC universe, disappeared after Crisis on Infinite Earth, a crossover that, with the aim of putting order into it, eliminated all the parallel Earths and prompted a reboot of all the characters. However, as evidence of the fact that a certain degree of cosmological consciousness never disappeared in the DC universe, it is advantageous to remember that the multiverse has reappeared in recent years, and that it has been reshaped by a series of crossovers which began in 2005 with Infinite Crisis and continued with 52, Countdown, Final Crisis, Flashpoint, and The New-52. Lastly, these periodical crises too, as well as the reboots and the systemic changes, belong to the mythical perspective of degradation of a perfect original state, ${ }^{5}$ and obey the idea that, when the world moves too far away from the perfection of the beginning, a catastrophe has to come, a crisis that, at the same time, represents "the sign announcing the imminent recreation of the World" (Eliade 60).

As for Marvel, in recent years, in an effort to develop the mythical potential of its characters, it has adopted some narrative features traditionally typical of DC. In particular, alternative fictional worlds have emerged, such as the experiment of 2099, the Marvel Noir series (which adopts an iterative narrative pattern), the Marvel Mangaverse, where the Marvel universe is represented in the manga style, and most notably, the Ultimate Marvel universe, which consists of different series dedicated to new versions of the principal characters. For these reasons, Henry Jenkins sees a shift in the Marvel universe from continuity to what he calls multiplicity, a new system under which "readers may consume multiple versions of the same franchise, each with different conceptions of the character, different understandings of their relationships with the secondary figures, different moral 
perspectives, exploring different moments in their lives, and so forth" (20-21). However, from the perspective adopted here, it is important to highlight that, unlike the DC universe, what happens in the Marvel parallel worlds does not have an impact on the main one, Earth-616, whose continuity has always remained quite strict, which is something that demonstrates Marvel's lasting commitment to an historical continuity.

In conclusion, it can be affirmed that the tendency toward one pole of temporality or another appears to be one of the decisive elements in the historical development of the DC and Marvel universes' architecture. Some important publishing operations in the superhero domain can be traced back to a more "historical" or "cosmological" consciousness, which originates from the kind of seriality adopted over the years. The respective universes of Marvel and DC appear to be more similar now than they were years ago, and this is probably caused by the simple reason that, from the point of view of the narrative possibilities, each model has advantages and disadvantages. However, as the ever-present tendency toward iterativity of the DC series and the constant attention toward continuity from Marvel demonstrate, the two opposite temporal approaches continue to permeate the logic at the base of the universes of these two publishing houses. As a result, the study of temporality acts here as an advantageous way of approaching the history of these systems and provides an understanding of their identity as two reciprocally constructed semiospheres.

\section{Notes}

1. The minor plasticity of the Marvel superheroes depends, once more, on the kind of seriality adopted. Clearly, the greater attention toward continuity causes the various interpretations of characters to be more constant and less changeable over the years than is seen in the DC universe. Generally, in Marvel's case, it is more complicated to modify the symbolical elements of the characters and so their psychological characteristics are played with more. Nevertheless, we cannot say that these superheroes do not possess a certain "mythical" elasticity.

2. To corroborate this statement, we can observe that the historiographical current of "virtual History" (or "counterfactual History") is based on the same "what if" method, and its working hypotheses sound very much like a Marvel imaginary tale: "What if there had been no English Civil War? What if there had been no American War of Independence? What if Ireland had never been divided? What if Britain had stayed out of the First World War? What if Hitler had invaded Britain? What if he had defeated the Soviet Union? What if the Russians had won the Cold War? What if Kennedy had lived? What if there had been no Gorbachev?" (Ferguson 2). On closer inspection, the purpose of exploring the alternative paths 
of history appears to be not very different from the goal of Michel Foucault's archeology of knowledge, which aims to reconstruct the conditions of possibility of history. According to the French philosopher, "we must grasp [a] statement in the exact specificity of its occurrence; determine its conditions of existence, fix at least its limits, establish its correlations with other statements that may be connected with it, and show what other forms of statement it excludes" (28). In this way, it would be possible to find out "the rules of formation" of the discourse, an ambition that seems implicit in the What if. ..? practice of Marvel.

3. From the point of view of the enunciation theory (Benveniste), the mere presence of a narrator is relevant because this figure's position stays "outside" the story he tells (which is, in technical terms, an "uttered enunciation"). So, in relation to the latter, the narrator is situated at the same semiotic side of the reader and he belongs to a more external, and more "real," layer of reality. This contributes to the solidity of the fictional universe and, once again, it is not surprising that a narrator appears in the "imaginary stories" of a very organized fictional world like Marvel's, and it is not present in the case of the less coherent DC Universe.

4. The Golden Age expression refers to the earliest superhero comics, which starts with the appearance of the first Superman story in Action Comics n. 1, dated June 1938. In the early 1940 s, a huge number of superhero characters sprung up, along with a large number of publishing houses that released this kind of comic. However, after the war, the genre suffered a terrible crisis and, in the middle of the 1950s, only three superheroes were still published in a magazine exclusively dedicated to them: Superman, Batman and Wonder Woman, all of them from DC comics. In 1956, DC started to produce new versions of the old heroes, which reappeared with new identities, different costumes, distinct origins of their superpowers, and other little changes. This date indicates the dawn of a new era, called the Silver Age, and, in the beginning, it was as if the old versions never existed. Nevertheless, starting with Flash of Two Worlds!, a comic published in September 1961, it was established that these characters lived in a parallel universe, and stories in which Flash, Superman, and other superheroes met their old versions began to appear. For a good account of the Golden Age comics see the classic Steranko, "The Steranko History of Comics;" for the Silver Age, the best reference is probably Jones and Jacobs, "The Comic Book Heroes".

5. This idea is also clearly reflected in the commonly accepted periodization of the history of superheroes - first conceived in the fandom and relative to the comics of both Marvel and DC - which is divided into Golden Age, Silver Age, Bronze Age, and Modern Age.

\section{Works Cited}

Arnaudo, Marco. The Myth of the Superhero. Trans. Jamie Richards. Baltimore: Johns Hopkins UP, 2013. Print.

Barbieri, Daniele. "Tempo, immagine, ritmo, racconto: Per una semiotica della temporalità nel testo a fumetti”. Diss. University of Bologna, 1992. Print.

Benveniste, Émile. "L'appareil formel de l'énonciation." Langages 17 (1970): 12-18. Print.

Bloch, Marc. French Rural History: An Essay on its Basic Characteristics. Trans. Janet Sondheimer. Berkeley: U of California P, 1966. Print.

Duncan, Randy, and Matthew J. Smith. The Power of Comics: History, Form, and Culture. New York: Continuum, 2009. Print. 
Eco, Umberto. "The Myth of Superman." The Role of the Reader: Explorations in the Semiotics of Texts. Trans. Natalie Chilton. Bloomington: Indiana UP, 1979. 107-24. Print.

Eliade, Mircea. Myth and Reality. Trans. Willard R. Trask. New York: Harper \& Row, 1963. Print.

Ferguson Niall, ed. Virtual History: Alternatives and Counterfactuals. London: Macmillan, 1997. Print.

Foucault, Michel. The Archaeology of Knowledge. Trans. A. M. Sheridan Smith. New York: Pantheon Books, 1972. Print.

Jenkins, Henry. “Just Men in Tights': Rewriting Silver Age Comics in the Age of Multiplicity."The Contemporary Comic Book Superhero. Ed. Angela Ndalianis. New York: Routledge, 2009. 16-43. Print.

Jones, Gerald, and Will Jacobs. The Comic Book Heroes: The First History of Modern Comic Books from the Silver Age to the Present. Rocklin, CA: Prima, 1996. Print.

Lotman, Yuri. La semiosfera I: Semiótica de la cultura y del texto. Madrid: Cátedra, 1996. Print.

—_. "On the semiosphere." Sign Systems Studies, 33.1 (2005): 20529. Print.

Meletinski, Eleazar. El mito: Literatura y folklore. Madrid: Akal, 2001. Print.

Pustz, Matthew J. Comic Book Culture. Fanboy and True Believers. Jackson: UP of Mississippi, 1999. Print.

Reynolds, Richard. Superheroes: A Modern Mythology. Jackson: UP of Mississippi, 1992. Print.

Romagnoli, Alex S., and Gian S. Pagnucci. Enter the Superheroes: American Values, Culture and the Canon of Superhero Literature. Lanham, MD: Scarecrow Books. 2013. Print.

Steranko, James. The Steranko History of Comics. 2 vols. Reading, PA: Crown, 1970 and 1972. Print.

Uspenskij, Boris. Storia e semiotica. Milano: Bompiani, 1987. Print.

Marcello Serra teaches at the Carlos III University in Madrid and his main interests are in semiotics and media theory. He has published several articles on superhero comics and, among other subjects, he has written about transparency, social movements, and Diego Maradona as a contemporary idol. 